\title{
A Nipple Splint Using a Textile-Like Thermoplastic Cast
}

\section{Seo Hyung Lee, Donghun Lee, Yu Jin Kim}

Department of Plastic and Reconstructive Surgery, Gachon University Gil Medical Center, Incheon, Korea
No potential conflict of interest relevant to this article was reported.
Nipples are protected by nipple splints after reconstructing or reshaping them using various materials. We have devised a nipple splint using textile-like thermoplastic tape, which is made out of knitted hybrid fabric, is latex-free, and keeps its position well beneath a brassiere with simple taping. Its conformation is readily modifiable according to each patient's breast shape, if it is soaked into hot water. A patient who underwent nipple reconstructive surgery had this thermoplastic cast applied for a month, and the contour of the nipple was well preserved without reports of skin irritation or pressure sores developing on the areola.

Keywords Casts surgical, Nipples, Splints, Textiles

\section{INTRODUCTION}

The demand for nipple reconstruction has been increasing with the proliferation of breast reconstruction. After reconstructing a nipple, it is crucial to apply a splint because one of the limitations of nipple reconstruction is loss of nipple projection over time [1]. Long-term projection of the reconstructed nipple is influenced by two factors: 1) contraction of the flap, which begins once the flap is raised; and 2) retraction of surrounding and underlying tissues [2]. External forces such as those from trauma can also distort the reconstructed nipple, leading to loss of projection. Therefore, a protective splint is necessary to ensure a successful outcome of this delicate reconstructive procedure. Currently, several different kinds of splint materials are available, each with its own benefits and drawbacks. We have devised a nipple splint using textile-like thermoplastic tape.

\section{IDEA}

Two pieces of 10-cm-long Orficast ${ }^{\mathrm{TM}}$ (Orfit industries, Wijnegem,

Received: Jun 21, 2016 Revised: Jul 21, 2016 Accepted: Jul 22, 2016 Correspondence: Yu Jin Kim Department of Plastic and Reconstructive Surgery, Gachon University Gil Medical Center, 21, Namdong-daero 774 beon-gil, Namdong-gu, Incheon 21565, Korea.

E-mail: pseugene@gilhospital.com

Copyright @ 2016 The Korean Society for Aesthetic Plastic Surgery.

This is an Open Access article distributed under the terms of the Creative Commons Attribution Non-Commercial License (http://creativecommons.org/licenses/by-nc/4.0/) which permits unrestricted non-commercial use, distribution, and reproduction in any medium, provided the original work is properly cited. $\quad$ www.e-aaps.org
Belgium) are prepared; one with a 6-cm width (wide tape) and another with a 3-cm width (narrow tape). To place a window in the splint, an "I"-shaped cut is made in the middle of the wide tape as shown in Fig. 1A. The size of the cut depends on that of the mold to be used.

The pieces of thermoplastic tape are soaked in $65^{\circ} \mathrm{C}$ water for 3 minutes and a mold, such as a plastic bottle cap, is positioned at the window of the wide tape (Fig. 1B and 1C). Then the narrow tape is placed on top of the cap. Different kinds of caps can be used to shape the splint depending on the nipple size. The two pieces of tape are adhered to each other by gently pressing them together.

After the cast stiffens, the mold is removed and the edges are trimmed for final application to the reconstructed nipple (Fig. 1D). The pieces of tape tend to shrink a little.

A patient with a history of breast reconstruction by free transverse rectus abdominis myocutaneous (TRAM) flap underwent a $\mathrm{C}-\mathrm{V}$ flap procedure to reconstruct the nipple on the ipsilateral breast. After the operation, the reconstructed nipple was protected with the Orficast ${ }^{\mathrm{TM}}$ for a month, and the contour was well preserved (Fig. 2). No skin irritation or pressure sore was noted until complete recovery.

\section{DISCUSSION}

Orficast ${ }^{\mathrm{TM}}$ was originally manufactured for finger splints and supportive bandage wrapping. However, it can be used in not only for nipple reconstruction procedures such as inverted nipple reconstruction and the C-V flap, but for also for nipple support after skin sparing mastectomy.

Orficast $^{\mathrm{TM}}$ is constructed of knitted hybrid fabric, is latex-free, 

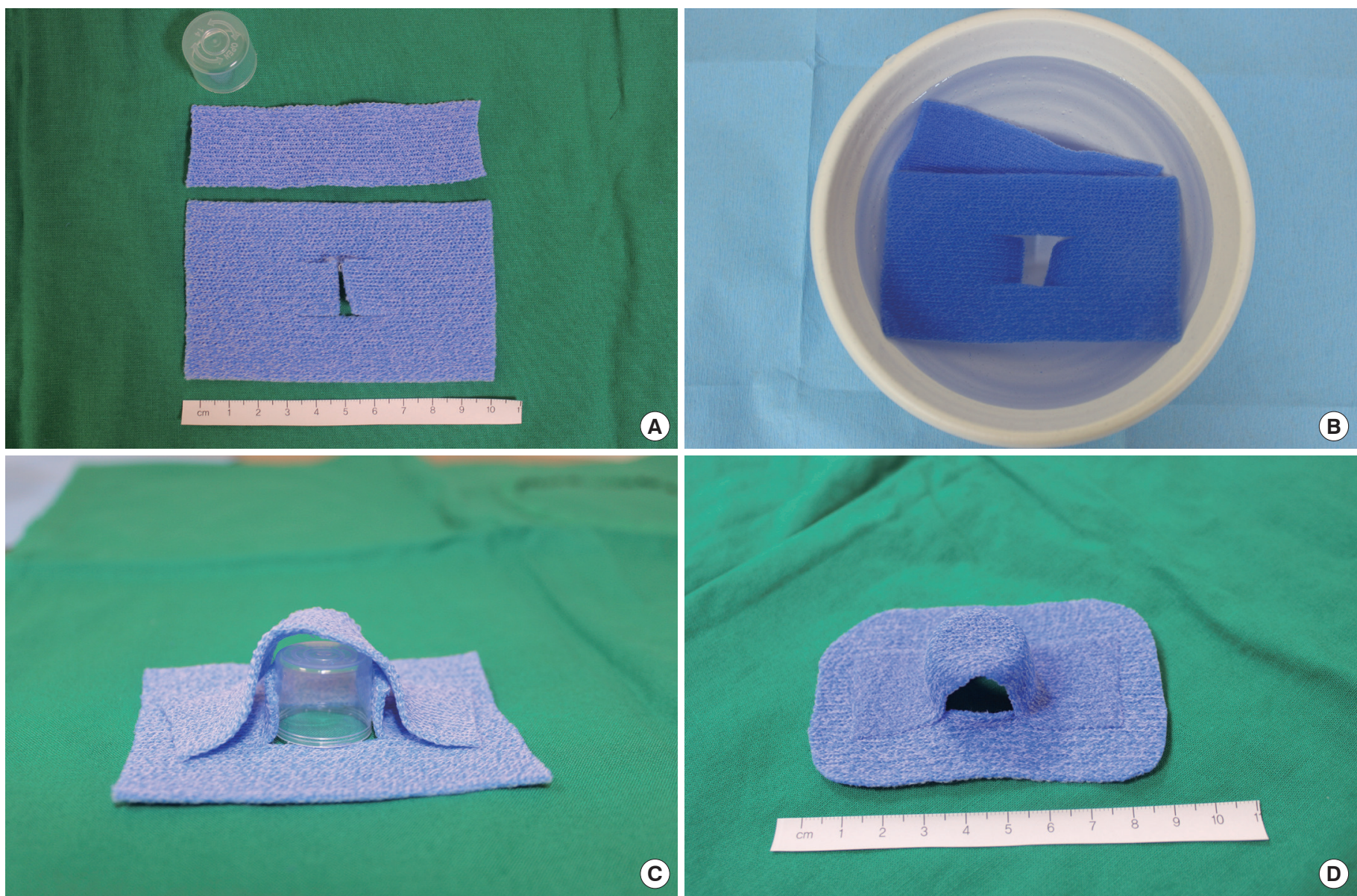

C

Fig. 1. (A) How to construct a nipple splint. A plastic bottle cap and two pieces of Orficast ${ }^{\mathrm{TM}}$ are prepared-6-cm- and 3-cm-wide pieces of tape, each $10 \mathrm{~cm}$ in length. $(B, C)$ They are soaked into $65^{\circ} \mathrm{C}$ water and a mold is positioned at the window, (D) then trimmed for use after they stick together and stiffen.

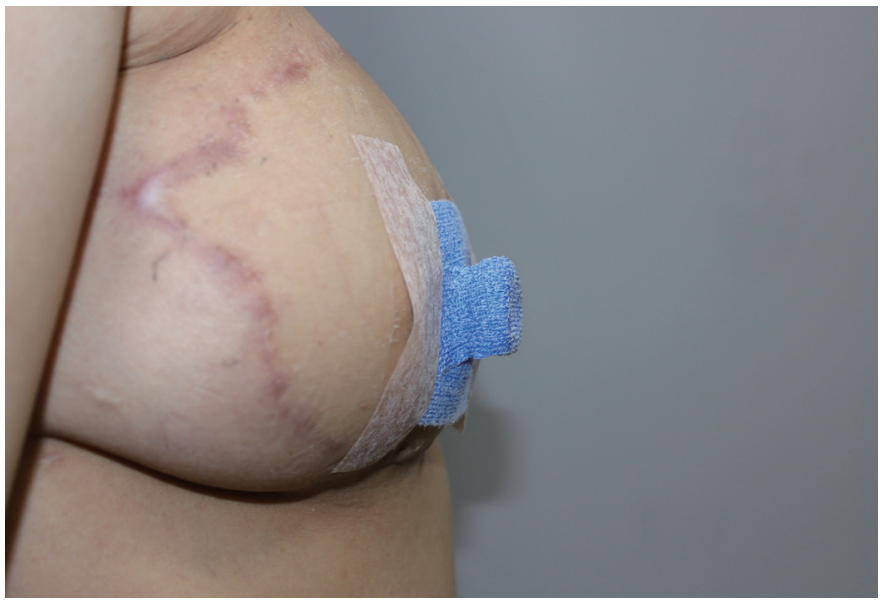

Fig. 2. The reconstructed nipple is protected by Orficast ${ }^{\mathrm{TM}}$ and the simple application of tape is used for fixation.

and maintains its position well beneath a brassiere with simple taping. Even after it stiffens, a certain degree of flexibility remains, which prevents pressure sores from developing on the areola.

The nipple splint must readily conform to the tissues to protect them from external shearing forces, must be easy to apply and remove without causing damage, and must not deform the nipple [3]. So far, a nipple splint prepared by cutting certain portions of a disposable plastic syringe has been used widely, but the plastic syringe is firm, making it difficult to cut and injury from its sharp crosssection is a concern. In addition, the blood supply around the areola may be compromised due to its inflexibility and bulkiness, and effectively securing it is troublesome. Use of a splint made of aqua splint is another common source of nipple protection [4]. However, it is difficult to manipulate, and its inflexibility can cause pressure sores. Using Orficast ${ }^{\mathrm{TM}}$, on the other hand, allows simple manipulation with scissors. A drawback is that it can be readily contaminated if post-operative bleeding persists.

\section{PATIENT CONSENT}

Patients provided written consent for the use of their images. 


\section{REFERENCES}

1. Khan K, Chevray PM. A rapid, simple, effective, and inexpensive reconstructed nipple flap guard. Plast Reconstr Surg Glob Open 2015;3: e546.

2. Rosing JH, Momeni A, Kamperman K, et al. Effectiveness of the Asteame Nipple Guard in maintaining projection following nipple reconstruction: a prospective randomised controlled trial. J Plast Recon- str Aesthet Surg 2010;63:1592-6.

3. Spear SL, Beckenstein MS. The nipple guard: an alternative covering for nipple-areola reconstructions with or without skin grafts. Plast Reconstr Surg 1997;100:1509-12.

4. Caviggioli F, Ventura D, Andretto Amodeo C, et al. Inverted nipple: use of an effective and personalized splint after surgical correction with Pitanguy's technique to avoid relapse of the inversion in 28 cases. Plast Reconstr Surg 2008;121:139e-40e. 